\title{
Improvement strategy of overcharging characteristics of a new type lithium iron phosphate battery in substation
}

\author{
Wei Kai ${ }^{1}$, Liu yunsong ${ }^{1}$, Rong Hua ${ }^{1}$, Qiu Peng ${ }^{1}$, Meng Zhen ${ }^{1}$ \\ ${ }^{1}$ Jinzhou Power Supply Branch of State Grid Liaoning Electric Power Co., LTD, JinZhou, 121000, China
}

\begin{abstract}
In order to solve the hidden trouble for the long-term overcharging condition of lithium iron phosphate batteries, it is urgent to develop overcharging protective lithium iron phosphate batteries. A strategy combining autonomous equalization technology and passive equalization technology is proposed in this paper to improve the overcharging characteristics of lithium iron phosphate batteries. A certain proportion of oxidizing reductant is added to the electrolyte of ordinary lithium iron phosphate battery. And a comparative test is conducted between conventional lithium iron phosphate battery module and selfequalization lithium iron phosphate battery module in continuous overcharging state. The test results show that the proposed comprehensive strategy has reduced the voltage difference between the cells significantly, and the single cell voltage difference is small in the long-term overcharging process, so as to maintain the safe voltage level.
\end{abstract}

\section{Introduction}

Lithium iron phosphate battery is a potential substitute for lead-acid battery as de power supply in substation. It is expected that with the improvement and maturity of the key manufacturing technology of lithium iron phosphate batteries, lithium iron phosphate batteries are likely to replace lead acid batteries and become the mainstream choice of DC power supply in the future power system. However, as the design prototype of lithium iron phosphate battery is a starting battery for frequent charging and discharging, it is necessary to improve the overcharging charging characteristics of lithium iron phosphate battery by converting it into a DC power supply operating normally in the mode of overcharging charging.

Literature [1] compared lead-acid battery and lithium iron phosphate battery from the aspects of conventional performance, temperature characteristic, life characteristic, rate discharge performance, etc. Literature [2] reported the calculation method of capacity configuration of lithium iron phosphate batteries used in dc system of substation. Reference [3] designs a dc system of lithium iron phosphate battery based on parallel diode for automatic time-delay switching. Literature [4] calculated the cost of using lithium iron phosphate battery in dc substation system, put forward the three-stage charging management method of constant current charging -- voltage limiting charging -supplementary charging. Reference [5] studied the operation mode of lithium iron phosphate battery used in dc power supply system of substation, and proposes a non-overcharging charging mode in which the charging device only supplies regular load in normal time and the battery pack is recharged when necessary. However, key parameters such as battery charging voltage, charging interval time and whether the operation mode meets the requirements of the power system are not clear. Reference [6] studied the accelerated aging test method at high temperature and high voltage to evaluate the service life of lithium-ion batteries as backup power sources.

The above literatures focused on the performance comparison between lithium iron phosphate batteries and lead-acid batteries, as well as the feasibility study of lithium iron phosphate batteries applied in de system of substation, but the working mode and operation characteristics of lithium iron phosphate batteries applied in DC system of substation have not been reported. The design prototype of common lithium iron phosphate battery is not suitable for continuous overcharging charging operation. When the common lithium iron phosphate battery is overcharged, too many lithium ions are released from the cathode material, and the excess lithium ions are forced into the carbon anode structure or deposited on the carbon surface to form lithium dendrites, which gradually collapses the structure of the cathode material and causes permanent damage to the electrode structure. At the same time, the electrolyte composition in the cathode surface of high potential irreversible oxidation decomposition, produce gas and give off a lot of heat, resulting in a sharp rise in the battery pressure and temperature, resulting in safety hazards.

*Corresponding author's e-mail: yao_jc@126.com 


\section{Electrochemical - thermal coupling model for lithium iron phosphate cells}

Since overcharging in substations is the biggest security hidden danger caused by long time overcharging fever security problems, based on the $\mathrm{NCM}(111)$ cells, for example statement inside the battery in the process of working process, the introduction of the build process of electrochemistry and thermal theory model, including various heat sources and heat exchange with the outside world of conditions and the material between the thermal conductivity;

To function properly, a battery must form a conductive circuit. On the outside, electrons travel through a wire. While on the inside, electrons $\mathrm{Li}^{+}$travel and combine. When the electrons are transferred from the external circuit to the active particles and conducting agents by collecting fluid, it involves the transmission process of electrons in the active particles and conducting agents. The diffusion and migration of the $\mathrm{Li}^{+}$in the electrolyte is involved when it is transported from the active particle to the opposite electrode. When $\mathrm{Li}+$ and electrons meet at the surface of the particle and react with each other, it involves an electric double-layer charge and discharge process. When Li diffuses in the active particle, it involves the diffusion process of $\mathrm{Li}$ in the active particle.

To function properly, a battery must form a conductive circuit. On the outside, electrons travel through a wire. While on the inside, electrons $L i+$ travel and combine. When the electrons are transferred from the external circuit to the active particles and conducting agents by collecting fluid, it involves the transmission process of electrons in the active particles and conducting agents. The diffusion and migration of the $\mathrm{Li}^{+}$in the electrolyte is involved when it is transported from the active particle to the opposite electrode. When $\mathrm{Li}+$ and electrons meet at the surface of the particle and react with each other, it involves an electric double-layer charge and discharge process. When Li diffuses in the active particle, it involves the diffusion process of $\mathrm{Li}$ in the active particle.

1) The process of force diffusion inside the active particle

In the case of particle insertion into $\mathrm{Li}$, the $\mathrm{Li}{ }^{+}$near the active particle contacts the electron on the particle surface to form $\mathrm{Li}$, which results in a high concentration of $\mathrm{Li}$ on the particle surface and a low concentration of $\mathrm{Li}$ inside the particle, thus forming a gradient of $\mathrm{Li}$ concentration inside the particle. Driven by the concentration gradient of $\mathrm{Li}, \mathrm{Li}$ will be transported from the surface to the center, which is called the internal $\mathrm{Li}$ diffusion process of active particles. Fick's Second Law is generally used to establish this process. It can be known from the hypothesis that the active particles are regarded as spherical particles of the same size, so the spherical coordinate system is selected to build the process, specifically as follows:

$$
\frac{\partial C_{s}}{\partial t}+\nabla \cdot \mathrm{J}_{S}=0
$$

where, $C_{s}$ represents the concentration of $L i$ inside the active particle and the flux of $\mathrm{Li}$ inside the particle, as shown in Formula 1, which is determined by the concentration difference. In this paper, the subscripts $s$ and $l$ represent the active particle and electrolyte respectively.

$$
\mathrm{J} s=-\mathrm{D}_{\mathrm{s}} \nabla C_{s}
$$

where, $D_{s}$ represents the diffusion coefficient of $L i$ in the active particle. Taking the positive particle as an example, the boundary condition of Equation 3 is:

$$
\left.D_{s, p} \frac{\partial C_{s}}{\partial r}\right|_{r=0}=0,\left.D_{s, p} \frac{\partial C_{s}}{\partial r}\right|_{r=R_{s, p}}=-i_{\mathrm{int}, p}
$$

where, $D_{s, p}$ denotes the radius of the active particle, $i_{\text {int, } p}$ denotes the local current density at the particeelectrolyte interface, and the subscripts $p$ and $n$ in the paper represent the positive and negative poles respectively.

2) The transfer process of active particles electron

Electronic transport within the active particles, active particles the current density of a given location $i_{S}$ by ohm's law definition: driven by the potential difference within the particle.

$$
i_{S}=-\sigma_{S} \nabla \phi_{S}
$$

where, the $\sigma_{s}$ is active electronic conductivity of granular material, and $\phi_{s}$ is particle potential for activity.

Taking the positive particle as an example, the boundary condition of Equation 5is:

$$
\left.\sigma_{S, p} \frac{\partial \phi_{S}}{\partial \mathrm{x}}\right|_{X=x_{L, p}}=-\frac{1}{A},\left.\sigma_{s, p} \frac{\partial \phi_{S}}{\partial x}\right|_{x=x_{g, p}}=0
$$

where, $I$ is the working current, $A$ is the section area, $x$ is the coordinates in the direction of thickness, $x=x_{1, p}$ is the fluid set position of the positive pole, and $x_{g, p}$ is the position near the diaphragm of the positive pole.

3) The electrolyte electrochemical reaction process of active particles

It is a key process in establishing the battery's conductive loop, and also a hinge connecting electrons to the $\mathrm{Li}^{+}$. It occurs only at the active particle-electrolyte interface, and involves local interactions with the exchange current density and over-potential. BulterVolmer relation is used to set up the complex process, the local current density $i_{\text {int }}$ expression is as follows:

$$
i_{\text {int }}=i_{0}\left\{\exp \left(\frac{\alpha_{n} F}{R T} \eta\right)-\exp \left(-\frac{\alpha_{p} F}{R T} \eta\right)\right\}
$$

where, $\alpha_{n}$ and $\alpha_{p}$ represent the charge transfer coefficient of negative and positive poles respectively, $F$ represents Faraday constant, $R$ represents the general gas constant $(8.314 \mathrm{~J} / \mathrm{K} / \mathrm{mol})$, and $\mathrm{T}$ represents temperature. Exchange current density $\mathrm{T}$ and the local surface 
potential $\eta$. They are calculated by equations (7) and (8) respectively

$$
\begin{gathered}
i_{0}=F k_{0}\left(C_{1}\right)^{\alpha_{n}}\left(C_{s, \max }-C_{s, \text { surf }}\right)^{\alpha_{n}}\left(C_{s, \text { surf }}\right)^{\alpha_{p}} \\
\eta=\phi_{s}-\phi_{1}-U_{e q}
\end{gathered}
$$

where, $k_{0}$ represents the reaction rate constant, $C_{s, \max }$ represents the maximum embeddable $L i$ concentration in the active electrode, $C_{s, \text { surf }}$ represents the $\mathrm{Li}$ concentration on the surface of the active particle, and $U_{e q}$ represents the open circuit potential.

Because the battery is neutral, the number of electrons passing through the electrolyte during charging must equal the number of electrons carried inside the particle. Therefore, the boundary conditions at the interface between electrolyte and active particle and the interface between active particle and active particle are as follows:

$$
\begin{aligned}
& i_{s} \cdot n_{s}=i_{\text {int }} \\
& i_{1} \cdot n_{1}=-i_{\text {int }}
\end{aligned}
$$

where, $n_{l}$ is the unit normal vector between the electrolyte and the active particles, and $n_{s}$ is the unit normal vector between the particles.

And the actual current density at any position is the sum of $i_{s}$ and $i_{l}$, namely:

$$
i_{1}+i_{s}=\frac{1}{A}
$$

Taking positive extreme as an example, the boundary condition of Equation 12 is:

$$
\begin{gathered}
\left.i_{1}\right|_{X=x_{1}}=0,\left.\frac{\partial i_{1}}{\partial \mathrm{x}}\right|_{X=x_{S}}=\frac{1}{A} \\
\left.i_{S}\right|_{X=x_{1}}=\frac{1}{A},\left.\frac{\partial i_{S}}{\partial \mathrm{x}}\right|_{X=x_{S}}=0
\end{gathered}
$$

\section{Self-balancing strategy for overcharging lithium iron phosphate batteries}

A certain proportion of oxidizing reductant is added to the electrolyte of ordinary lithium iron phosphate battery. The anode material of over charge lithium iron phosphate

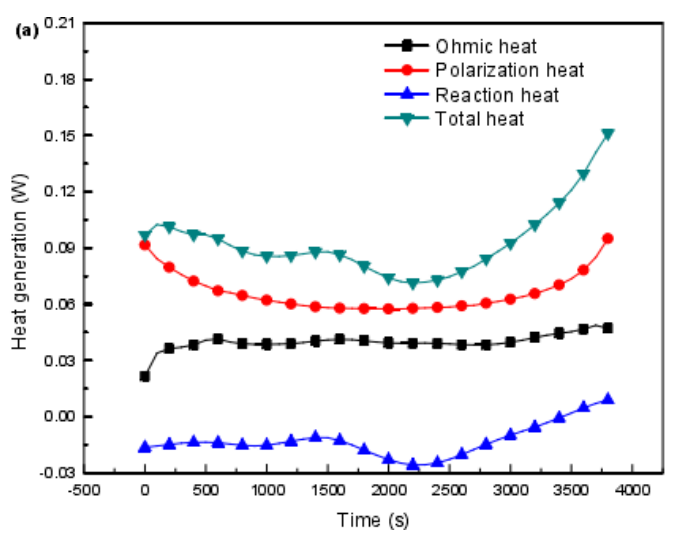

battery is a kind of compound embedded with lithium, and the main material is lithium iron phosphate (LiFePO4). $\mathrm{Li}+$ in the compound can be detached and embedded from the lattice under the external electric field. The main material of the negative electrode is carbon $\mathrm{C}$, and the electrode is infiltrated into the organic solvent of lithium LiPF6 salt in the electrolyte. At the same time, the oxidation-reducing agent can move back and forth between the anode and cathode of the lithium ion battery in a certain voltage range to complete oxidation and reduction.

In the continuous over-charging state, the oxidizing reducing agent is stable in the electrolyte and does not participate in any chemical or electrochemical reaction, which has no influence on the macro electrochemical performance of the battery. When the battery voltage reaches or exceeds upper limit voltage $(3.85 \mathrm{~V})$, the redox status are oxidized in the surface of the anode. The oxidation products spread to the reduction of the cathode surface reduction product, and then spread to the anode oxidation. The whole process circulates along the oxidation, reduction and diffusion. In the process of charging, the charging current only carry through reversible redox reaction, overcharge power neither was stored in two electrodes, also didn't used to the irreversible oxidative decomposition of the electrolyte, only accompanied by redox reaction is released in the form of heat, make the battery voltage rise faster in the battery is not charging. And, other batteries can also be charged normally, eventually achieving a balanced charge effect.

\section{Simulation analysis}

The experimental system used in this paper is a self-built experimental system using a combination of high and low temperature test box, charge and discharge test system and temperature meter.

Since the biggest danger of over rechargeable batteries lies in the fire caused by heat, it is necessary to analyze the single heat transmission law of over recharged lithium iron phosphate batteries.

\subsection{Analysis of the influence of charge and discharge on the heat generation and heat transfer of overcharging lithium iron phosphate batteries}

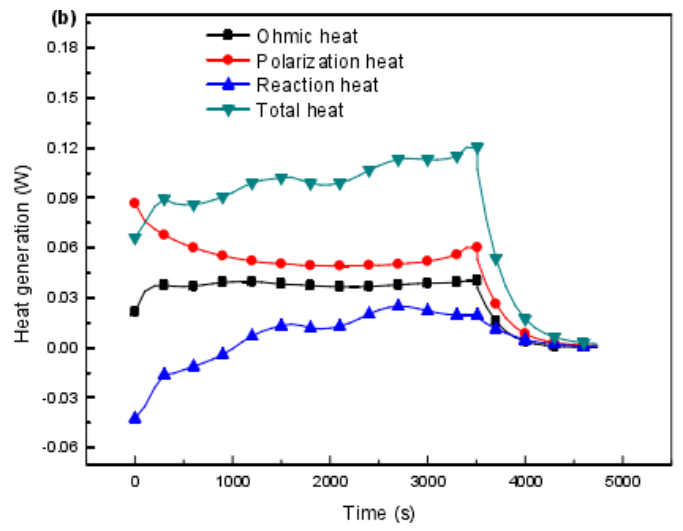

Fig.1 Comparison of simulation and experiment in battery discharge process: (a) Discharge 1C; (b) Charge 1C 
The heat generation of over charge battery is mainly generated by three parts, namely the reaction heat $\mathrm{Q}_{\mathrm{rec}}$, also known as entropy $\mathrm{Ohm}$ heat $\mathrm{Q}_{\text {ohm}}$; And the polarization heat $\mathrm{Q}_{\text {act. }}$ The reaction heat of the battery is reversible, which is determined by the entropy thermal characteristics of the positive and negative electrode plates of the battery. The ohmic heat and polarization heat of the battery are irreversible heat, which are mainly determined by the ohmic internal resistance and polarization internal resistance of the battery. The heat dissipation term of the battery is mainly composed of two parts, namely the convective heat transfer and

Tab.1 Test results of terminal voltage deviation of self-equalizing lithium iron phosphate battery in over charging state

\begin{tabular}{|c|c|c|c|c|c|c|c|c|c|c|c|c|c|c|}
\hline \multirow{2}{*}{\multicolumn{2}{|c|}{$\begin{array}{l}\text { Over- } \\
\text { charging } \\
\text { time } \\
\text { /week }\end{array}$}} & \multicolumn{12}{|c|}{ Measured value of terminal voltage of single battery $/ \mathrm{V}$} & \multirow{3}{*}{$\begin{array}{c}\text { deviation } \\
/ \mathrm{V}\end{array}$} \\
\hline & & \multicolumn{2}{|c|}{$1^{\#}$} & \multicolumn{2}{|c|}{$2^{\#}$} & \multicolumn{2}{|c|}{$3^{\#}$} & \multicolumn{2}{|c|}{$4^{\#}$} & \multicolumn{2}{|c|}{$5^{\#}$} & \multicolumn{2}{|c|}{$6^{\#}$} & \\
\hline \multirow{13}{*}{ 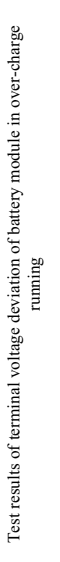 } & & $\begin{array}{c}\text { Conventio } \\
\text { nal } \\
\text { batteries }\end{array}$ & $\begin{array}{l}\text { Propos } \\
\text { ed } \\
\text { method }\end{array}$ & $\begin{array}{c}\text { Conventio } \\
\text { nal } \\
\text { batteries }\end{array}$ & $\begin{array}{l}\text { Propos } \\
\text { ed } \\
\text { method }\end{array}$ & $\begin{array}{c}\text { Conventio } \\
\text { nal } \\
\text { batteries }\end{array}$ & $\begin{array}{l}\text { Propos } \\
\text { ed } \\
\text { method }\end{array}$ & $\begin{array}{c}\text { Conventio } \\
\text { nal } \\
\text { batteries }\end{array}$ & $\begin{array}{l}\text { Propos } \\
\text { ed } \\
\text { method }\end{array}$ & $\begin{array}{c}\text { Conventio } \\
\text { nal } \\
\text { batteries }\end{array}$ & $\begin{array}{l}\text { Propos } \\
\text { ed } \\
\text { method }\end{array}$ & $\begin{array}{c}\text { Conventio } \\
\text { nal } \\
\text { batteries }\end{array}$ & $\begin{array}{l}\text { Propos } \\
\text { ed } \\
\text { method }\end{array}$ & \\
\hline & 0 & 3.307 & 3.315 & 3.307 & 3.315 & 3.316 & 3.315 & 3.348 & 3.321 & 3.373 & 3.322 & 3.630 & 3.322 & 0.329 \\
\hline & 1 & 3.306 & 3.304 & 3.306 & 3.304 & 3.328 & 3.304 & 3.346 & 3.312 & 3.345 & 3.312 & 3.630 & 3.312 & 0.334 \\
\hline & 2 & 3.310 & 3.304 & 3.310 & 3.304 & 3.346 & 3.303 & 3.349 & 3.310 & 3.349 & 3.312 & 3.616 & 3.312 & 0.327 \\
\hline & 3 & 3.315 & 3.304 & 3.315 & 3.304 & 3.348 & 3.304 & 3.358 & 3.312 & 3.358 & 3.313 & 3.603 & 3.313 & 0.315 \\
\hline & 4 & 3.321 & 3.304 & 3.321 & 3.304 & 3.349 & 3.303 & 3.463 & 3.310 & 3.447 & 3.312 & 3.586 & 3.312 & 0.179 \\
\hline & 5 & 3.331 & 3.304 & 3.333 & 3.304 & 3.346 & 3.303 & 3.504 & 3.310 & 3.442 & 3.312 & 3.459 & 3.312 & 0.179 \\
\hline & 6 & 3.346 & 3.304 & 3.346 & 3.304 & 3.352 & 3.303 & 3.531 & 3.310 & 3.417 & 3.312 & 3.445 & 3.312 & 0.185 \\
\hline & 7 & 3.348 & 3.304 & 3.346 & 3.304 & 3.355 & 3.303 & 3.525 & 3.310 & 3.435 & 3.312 & 3.400 & 3.312 & 0.179 \\
\hline & 8 & 3.348 & 3.307 & 3.348 & 3.307 & 3.364 & 3.307 & 3.484 & 3.315 & 3.442 & 3.316 & 3.402 & 3.316 & 0.136 \\
\hline & 9 & 3.340 & 3.304 & 3.340 & 3.304 & 3.409 & 3.304 & 3.412 & 3.312 & 3.414 & 3.313 & 3.414 & 3.312 & 0.099 \\
\hline & $\begin{array}{l}1 \\
0\end{array}$ & 3.348 & 3.304 & 3.349 & 3.304 & 3.486 & 3.304 & 3.532 & 3.312 & 3.478 & 3.313 & 3.453 & 3.312 & 0.184 \\
\hline & $\begin{array}{l}1 \\
1\end{array}$ & 3.348 & 3.304 & 3.348 & 3.304 & 3.520 & 3.304 & 3.568 & 3.312 & 3.454 & 3.313 & 3.400 & 3.312 & 0.220 \\
\hline
\end{tabular}

It can be seen from table 1, during conventional lithium iron phosphate battery module operation process of overcharging, for the case of overcharging monomer voltage is reached, the single highest voltage reaches $3.75 \mathrm{~V}$. And then, monomer battery voltage drops to balance point and basically remain unchanged. After around $0.45 \mathrm{~V}$ to $0.38 \mathrm{~V}$. monomer voltage deviation is about $15 \%$ lower. That illustrates the battery module inconsistencies have improved. But after reaching balance differential pressure stable gradually, the deviation of lower speed slower and slower;

From the above comparison, it can be seen that in the conventional battery module under overcharging management, the single battery with a high SOC in the battery module is maintained at a high voltage, while the single battery with a low SOC is maintained at a low voltage. The pressure difference decreases slowly and is not obvious. The long-term overcharging charge operation of conventional battery modules will lead to the battery with higher SOC to be maintained at higher voltage, which will bring great risks to the safety of battery modules. Since the equilibrium and passive equilibrium cell module monomer battery voltage compared to the conventional battery module maximum differential pressure is lesser, and through the overcharging phase equilibrium and the passive balanced management mode can significantly reduce the battery voltage difference between and long-term overcharging overcharging voltage deviation decreases by maximum radiation heat transfer between the battery boundary and the external environment.

\subsection{Analysis of voltage deviation of over-charge self-equalizing lithium iron phosphate battery module}

The 50 Ah conventional lithium iron phosphate batteries and $50 \mathrm{Ah}$ self-equalizing lithium iron phosphate batteries with 6 units each are taken to form two battery modules respectively. process, the monomer battery voltage difference is small, maintain the normal voltage level.

\section{Conclusion}

a) The test results show that under the long-term operation, the equilibrium of lithium iron phosphate battery SOC in the battery module high monomer voltage drops gradually to close to the overcharging average voltage module by balancing. For the monomer with lower SOC, the voltage gradually increases to approach the average voltage module. The management method of equilibrium effectively improves the battery module overcharging adaptability. This management method reduced the difference of battery under the operation of over charge, and improves the safety of over charge, and satisfies the working characteristics of dc power system of substation.

b) According to the requirements of dc power supply for power system, further research is needed before lithium iron phosphate battery can be fully recognized and widely used in power grid. Lithium iron phosphate battery charging due to its special effects and long-term application of over charge prone to battery overcharge phenomenon, so the traditional lithium iron phosphate batteries used in long-term overcharging there is a certain risk, to improve the lithium iron phosphate batteries in the long-term over state security analysis. 


\section{Acknowledgments:}

This work was supported in part by science and technology project of Liaoning province state grid corporation of China (2020YF-14)

\section{References}

1. Saw LH, YeY, Tay AAO. Eiectro-thermal analysis and integration issues of lithiumion battery for electric vehicles [J]. Applied Energy,2014,131:97107

2. Fleckenstein $\mathrm{M}$, Bohlen $\mathrm{O}$, Roscher $\mathrm{M} \mathrm{A}$, et al. Current density and state of charge inhomogeneities in Li-ion battery cells with $\mathrm{LiFeP04}$ as cathode material due to temperature gradients [J]. Journal of Power Sources, 2011, 196(10): 4769-4778.

3. Michelbacher C, Ahmed S, Bloom I, et al. Enabling fast charging-Introduction and overview[J]. Journal of Power Sources, 2017, 367:214-215.

4. Qu X H, Han H D, Wong S C, et al. Hybrid IPT Topologies With Constant Current or Constant Voltage Output for Battery Charging Applications[J]. IEEE Transactions on Power Electronics, 2015, 30(11):6329-6337.

5. Ahmed S, Bloom I, Jansen A N, et al. Enabling fast charging - A battery technology gap assessment[J].Journal of Power Sources, 2017, 367: 250-262.

6. Michelbacher C, Ahmed S, Bloom I,et al. Enabling fast charging-Introduction and overview [J]. Journal of Power Sources,2017,367:214-215. 